\section{Somatische Mutation}

\section{J. Arnemann}

Abteilung Molekulargenetik, Labor Dr. Wisplinghoff, Köln, Deutschland

Synonym(e) Spontane gewebemutation

Englischer Begriff somatic mutation

Definition Im Gegensatz zu Keimbahnmutationen entstehen somatische Mutationen spontan und betreffen nur bestimmte Zellreihen, können also, mit Ausnahme von De-novo-Keimzellmutationen, nicht weiter vererbt werden.

Beschreibung Somatische Mutationen sind mehrheitlich Fehler bei der DNA-Replikation mitotisch aktiver Zellen und werden als Transläsionssynthese (TLS) beschrieben. Unter TLS versteht man einen Prozess, der in einem gewissen Rahmen einen DNA-Schaden toleriert und eine DNAReplikation über DNA-Läsionen, wie z. B. Thymindimere oder AP-Abschnitte, hinweg erlaubt. Unter AP-Abschnitte versteht man in diesem Zusammenhang ein abasisches Molekül, das aufgrund von chemischen Noxen weder eine Purin- noch eine Pyrimidinbase (,apurinic/apyrimidic site“) besitzt. Ein wesentlicher Faktor sind dabei oxidative DNA-Schäden. Aber auch Fehler bei der DNA-Reparatur oder Mutationen aufgrund von mutagenen Agenzien können das Entstehen von somatischen Mutationen fördern.

Ein pathogener Effekt kann bevorzugt auftreten, wenn es sich um sehr teilungsaktive Zellen handelt und die Mutation zelluläre Funktionen, Regelkreise, Signalwege oder die DNAReparaturmechanismen grundlegend stört. Dies kann die zelluläre Differenzierung beeinträchtigen und zu einer Proliferation wenig differenzierter Zellen als möglichen Beginn einer Tumorerkrankung führen.

Bei erblichen Tumorerkrankungen, wie z. B. erblicher Brust- und Eierstockkrebs Typ BRCA1/2, bei denen bereits konstitutiv eine ererbte Mutation vorliegen, kann das Auftreten einer zweiten somatischen Mutation so die Krebsentstehung triggern, zumal es zu einem Komplettausfall der Funktion eines Tumorsuppressors kommt.

\section{Literatur}

Martincorena I, Campbell PJ (2015) Somatic mutation in cancer and normal cells. Science 349:1483-1489 